\title{
Erratum to: A comparison of various artificial intelligence approaches performance for estimating suspended sediment load of river systems: a case study in United States
}

Ehsan Olyaie • Hossein Banejad • Kwok-Wing Chau • Assefa M. Melesse

Published online: 24 April 2015

(C) Springer International Publishing Switzerland 2015

Erratum to: Environ Monit Assess (April 2015) 187, Issue 4:4381

DOI 10.1007/s10661-015-4381-1

The original article contained an error.

The affiliation of Dr. E. Olyaie is incorrect. The corrected affiliation is now shown below.

The online version of the original article can be found at http://dx. doi.org/10.1007/s10661-015-4381-1.

E. Olyaie

Young Researchers and Elite Club, Hamedan Branch, Islamic

Azad University, Hamedan, Iran

H. Banejad $(\bowtie)$

Department of Water Engineering, College of Agriculture, Ferdowsi University of Mashhad, Mashhad, Iran

e-mail: hossein_banejad@yahoo.com

K.-W. Chau

Department of Civil and Environmental Engineering, Hong

Kong Polytechnic University, Hong Kong, China

A. M. Melesse

Department of Earth and Environment, Florida International

University, Miami, FL, USA 